\title{
MENAKAR RESPON PENGGUNA INSTAGRAM TERHADAP PROGRAM "MATA NAJWA" MELALUI SISI DAN PANDANGAN POLITIK
}

\author{
Saifuddin Zuhri, Irvia Amananda dan Nanda Alya Karlina Amini dan Tiara \\ Febri Angellia \\ Universitas Pembangunan Nasional Veteran Jawa Timur, Indonesia \\ Email: saifuddin_zuhri.ilkom@upnjatim.ac.id, irvia.alvaro15@gmail.com, \\ alyakarlina@gmail.com, tiarafebryangellia202122@gmail.com
}

\begin{abstract}
This study aims to find out how the program 'Mata Najwa' is responded by Instagram users as an educational program from the Political side which is a bridge to deliver information and connect people and government. This type of research used in this study is quantitative that uses the Use and Gratification approach and is carried out using the Instagram Polling feature. In this study, the total respondents are 258 Instagram users. The results of this study indicate that the program has responded well, is considered to educate the people well, and is expected to always be there and broadcast. Most of the respondents thought the 'Mata Najwa' program was used as a reference to attend the news that was being discussed hotly. Based on the results of the study showed that Mata Najwa has a positive image and educational value in the eyes of Instagram users.
\end{abstract}

Keywords: 'mata najwa' program; instagram users; perception

\begin{abstract}
Abstrak
Penelitian ini bertujuan mengetahui bagaimanakah tayangan 'Mata Najwa' direspon oleh pengguna Instagram sebagai program edukasi dari sisi Politik yang menjadi jembatan penghantar informasi dan menghubungkan rakyat dan pemerintah. Tipe penelitian yang digunakan pada penelitian ini adalah kuantitatif yang menggunakan pendekatan Penggunaan dan Gratifikasi dan dilakukan dengan menggunakan fitur Instagram Polling. Dalam penelitian ini, total responden sebanyak 258 responden pengguna Instagram. Hasil penelitian ini menunjukkan bahwa program ini direspon baik, dianggap mengedukasi rakyat dengan baik, dan diharapkan selalu ada dan tayang. Sebagian besar para responden berpendapat acara 'Mata Najwa' dijadikan acuan untuk mengikuti pemberitaan yang sedang hangat diperbincangkan. Berdasarkan hasil penelitian menunjukkan bahwa Mata Najwa mempunyai citra yang positif dan nilai edukasi dimata pengguna instagram.
\end{abstract}

Kata kunci: program mata najwa; pengguna instagram; persepsi 
Coresponden Author

Email: saifuddin_zuhri.ilkom@upnjatim.ac.id Artikel dengan akses terbuka dibawah lisensi

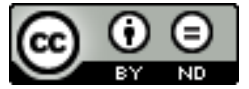

\section{Pendahuluan}

Manusia adalah makhluk sosial. Dan tentunya, kita sebagai manusia pasti tidak akan lepas dari komunikasi. Tidak lepas pula berhubungan dengan manusia lainnya. Komunikasi sangat erat dan penting dalam kehidupan sehari-hari. Kita berkomunikasi untuk mengutarakan, menyampaikan dan mentransfer ide, pikiran, gagasan, isi hati dan perasaan, membangun dan memelihara hubungan dengan manusia lainnya. Banyak sekali cara dan medium yang kita digunakan untuk berkomunikasi. Salah satu medium yaitu media massa. Media Massa adalah sarana komunikasi massa dimana proses penyampaian pesan, gagasan, atau informasi kepada orang banyak (public) secara serentak. Salah satu media sosial yang paling banyak digunakan masyarakat saat ini adalah Instagram. Instagram sebagai salah satu media sosial ini berfungsi dan peran besar bagi penggunanya, karena Instagram merupakan aplikasi yang memungkinkan pengguna mengambil foto, mengambil video, menerapkan filter digital, dan membagikannya ke berbagai layanan jejaring sosial, termasuk milik Instagram sendiri, serta memiliki sifat yang informatif, hiburan dan memberikan edukasi kepada pengguna.

Hal ini menjadikan informasi berkembang pesat dan juga muncul globalisasi teknologi informasi dimana pun yang bisa diakses lewat berbagai macam media sosial. Seiring berkembangnya jaman pula, media sosial berlomba-lomba untuk mempunyai karya terbaik yang akan disuguhkan kepada khalayak. Khalayak atau masyarakat membutuhkan media sosial berdasarkan atas motif-motif tertentu, karena itu media memenuhi kebetuhan khalayak adalah media yang efektif (Syahreza \& Tanjung, 2018). Schram dan Roberts juga menyatakan bahwa audience sangat aktif mencari apa yang mereka inginkan.

Pendekatan Uses and Gratification ditujukan untuk menggambarkan proses penerimaan dalam komunikasi massa dan menjelaskan penggunaan media oleh individu atau agregasi [kbbi; pengumpulan sebuah benda yang terpisah - pisah menjadi satu individu] (Effendy, Löffler, \& Maibach, 2000). Pengguna media adalah pihak yang aktif dalam proses komunikasi, pengguna media berusaha untuk mencari sumber media yang paling baik didalam usaha memenuhi kebutuhannya. Artinya, teori uses and gratifications mengasumsikan bahwa pengguna mempunyai pilihan alternatif untuk memuaskan kebutuhannya (Nuruddin, Madramootoo, \& Dodds, 2003).

Adapun beberapa penelitian terdahulu diantaranya, Penelitian Ari Musdolifah yang dilakukan pada tahun 2019 membahas mengenai tindak tutur representatif dalam acara Talk Show Mata Najwa di Trans 7 sebagai alternatif bahan ajar Bahasa Indonesia di SMP dengan dilatarbelakangi oleh banyaknya tindak tutur yang terjadi dalam kehidupan manusia yang dapat dimaknai berdasarkan konteks. Pendekatan yang 
Saifuddin Zuhri, Irvia Amananda dan Nanda Alya Karlina Amini dan Tiara Febri Angellia

digunakan dalam penelitian ini adalah pendekatan pragmatic. Wujud datanya adalah kata-kata dan kalimat dari tuturan yang dihasilkan oleh Sandiaga Uno Cawapres 2019 dengan nomor urut 02 yang terkait dengan jenis dan fungsi tindak tutur representatif. Sumber data penelitian ini adalah acara Talk Show Mata Najwa yang ditayangkan di Trans 7. Selain itu, teknik pengumpulan data penelitian ini menggunakan teknik simak dan catat untuk selanjutnya di analisis dengan metode padan pragmatis. Berdasarkan hasil dan pembahasan dapat disimpulkan bahwa 1) jenis dan fungsi yang terdapat dalam penelitian ini adalah jenis tindak tutur prediktif, retrodiktif, deskriptif, informatife, konfirmatif, retraktif, dissentif, disputatife, sugestif, dan suppositif, 2) alternatif tindak tutur representatif pada acara Talk Show Mata Najwa yang ditayangkan di Trans 7 sebagai bahan ajar bahasa Indonesia di SMP adalah dapat membantu peserta didik dalam menambah wawasan pengetahuan yang lebih luas tentang jenis dan fungsi tindak tutur representatif dan meningkatkan keterampilan peserta didik untuk memberikan komentar, berfikir kritis, dan kreatif terhadap tuturan tersebut

Penelitian yang dilakukan oleh Christo Rico Lado yang dilakukan pada tahun 2013 membahas mengenai analisis wacana kritis program Mata Najwa "Balada Perda" di Metro TV. Penelitian ini menggunakan teknik analisis wacana kritis model Teun van Dijk dan menemukan bahwa Mata Najwa membangun wacana bahwa perda melayani kepentingan pemerintah; perda mengintervensi privasi masyarakat; dan perda mendiskriminasi kelompok tertentu. Pembentukan wacana ini sekaligus menunjukkan pendefinisian dan penempatan posisi yang dilakukan Mata Najwa terhadap partisipan produksi wacana. Mata Najwa menempatkan Najwa Shihab sebagai pihak yang dominan sehingga realitasnya bisa diterima publik sebagai kebenaran. Dengan perpaduan analisis teks, kognisi sosial dan konteks, peneliti menemukan wacana yang dibangun Mata Najwa meneguhkan pandangan bahwa perda pasca otonomi daerah mengundang pro dan kontra dalam masyarakat. Peneliti juga menemukan bahwa tayangan Mata Najwa Balada Perda dipengaruhi oleh kepentingan ekonomi media Metro TV.

Penelitian yang dilakukan oleh Ilona V. Oisina Situmeang pada tahun 2016 membahas mengenai pengaruh program acara Mata Najwa terhadap pemenuhan kebutuhan informasi (survey mahasiswa Ilmu Komunikasi Universitas Bunda Mulia, Jakarta). Program acara yang menyajikan berbagai informasi penting tersebut apakah dapat memenuhi kebutuhan informasi bagi mahasiswa Ilmu Komunikasi Universitas Bunda Mulia, Jakarta. Pendekatan penelitian ini menggunakan pendekatan kuantitatif dan dikuatkan dengan pendekatan kualitatif. Dari hasil penelitian, yang dimana hasil uji korelasi yang dilakukan diperoleh hasil 0,717 yang artinya terdapat pengaruh yang kuat antara program acara Mata Nazwa terhadap pemenuhan kebutuhan informasi. Sedangkan dari uji regresi yang diperoleh sebesar 71,7\% program acara mempengaruhi pemenuhan kebutuhan informasi dan dari Uji hipotesis yang dilakukan didapatkan hasil Ha diterima dan Ho ditolak yang artinya terdapat pengaruh antara 
program acara Mata Nazwa terhadap pemenuhan kebutuhan informasi bagi mahasiswa Ilmu Komunikasi Universitas Bunda Mulia, Jakarta.

Penelitian yang dilakukan oleh Ravi Noldy Boer pada tahun 2019 membahas mengenai relationship marketing dan Mata Najwa sebagai bagian dari strategi memasarkan Narasi.tv dengan dilatarbelakangi oleh pertumbuhan pasar pengguna internet di Indonesia mendorong Najwa Shihab untuk membangun platform multi konten berbasis digital yang diberi nama Narasi.tv. Agar bisa lebih fokus membangun Narasi.tv, pada Agustus 2017 lalu, Najwa Shihab mengundurkan diri dari Metro TV, sekaligus mengumumkan berakhirnya tayangan program Mata Najwa yang sudah 9 tahun mengudara. Penelitian ini ingin memaparkan bagaimana program Mata Najwa turut berkontribusi dalam mempopulerkan Narasi.tv. Citra positif Mata Najwa, serta relationship marketing yang sudah terjalin lama dengan pemirsanya, telah menciptakan segmen penonton baru, yaitu para pengguna internet yang bisa mengaksesnya secara online hanya di Narasi.tv.

\section{Metode Penelitian}

Jenis penelitian yang digunakan adalah penelitian kuantitatif. Penelitian kuantitatif lebih mudah dimengerti karena dapat dijelaskan dengan angka-angka. Penelitian kuantitatif merupakan penelitian yang menggunakan analisis data yang berbentuk numerik/angka. Penulis menggunakan fitur Instagram Polling untuk melihat respon penonton program Mata Najwa. Melalui Instagram Polling ini didapatkan hasil berupa dalam bentuk persentase dan frekuensi pemilih dan penjawab pertanyaan yang dipaparkan di fitur Instagram polling.

\section{Hasil dan Pembahasan}

Dalam teori Uses \& Gratifications khalayak dipersepsikan sebagai objek yang aktif terhadap media. Teori ini adalah antitesis dari teori powerful effect atau jarum suntik yang menjelaskan bahwa media memiliki efek yang kuat dan besar terhadap khalayak. Dalam pemikiran Uses dan Gratification khalayak memiliki kesadaran penuh dalam memilih media untuk memenuhi kebutuhan dan keinginannya (West \& Turner, 2008).

Persepsi individu dimulai dari adanya perhatian atau atensi. Perhatian adalah syarat psikologi dalam individu mengadakan persepsi, yang merupakan langkah persiapan, yaitu kesediaan individu untuk mengadakan persepsi. Perhatian merupakan pemutusan atau konsentrasi dari seluruh aktifitas individu yang ditujukan kepada suatu objek atau sekumpulan objek (Tekkay, Himpong, \& Paputungan, 2017). Stimuli diperhatikan karena mempunyai sifat-sifat yang menonjol, antara lain: gerakan, intensitas stimuli, kebaruan, dan perulangan.

Stimuli ini dialami juga oleh informan yang tertarik setelah mereka melihat sekilas talkshow Mata Najwa. Setelah tiap informan menerima atensi (stimuli awal) tentang talkshow Mata Najwa, selanjutnya terjadi proses seleksi. Seleksi yang dimaksud adalah proses penyeleksian pesan, dimana individu akan memilah mana 
Saifuddin Zuhri, Irvia Amananda dan Nanda Alya Karlina Amini dan Tiara Febri Angellia

pesan yang dianggap penting dan tidak penting. Proses seleksi ini memunculkan alasan dari informan untuk menonton tayangan Mata Najwa. Mereka menganggap bahwa Mata Najwa merupakan tontonan yang penting untuk mereka sehingga mereka memutuskan untuk menontonnya.

Tingkat pengetahuan dan informasi pengguna Instagram terhadap program televisi Mata Najwa yang tayang di Trans7, dari hasil penelitian pada pertanyaan pertama menunjukkan bahwa 216 dari 258 responden memilih "KADANG KADANG" artinya mereka menyatakan bahwa tidak mengetahui tayangan program Mata Najwa dan 42 responden memilih "SETIAP EPISODE" artinya mereka mengetahui tayangan program Mata Najwa yang tayang di Trans7. Artinya, responden mengetahui tayangan program Mata Najwa yang di tanyangkan di Trans 7 dan minim sekali responden yang tidak mengetahui program tv Mata Najwa. Persentase responden mengetahui adanya program Mata Najwa menyentuh angka $92 \%$ dari total $100 \%$ responden.

Pada pertanyaan kedua, sebanyak 306 responden atau 80\% menjawab "HANYA MENONTON MATA NAJWA SAAT EPISODE MENARIK SAJA”. Responden menyatakan bahwa episode menarik dan sedang hangat diperbincangkan lebih menarik perhatian mereka saat menonton program Mata Najwa karena memberikan informasi yang valid saat terjadinya informasi yang simpang siur, dan menyatakan mereka sadar jika selama ini opini mereka mengikuti arus media, media memiliki peran yang sangat penting dalam menggiring opini masyarakat, khususnya pengguna Instagram. Persentase $80 \%$ atau 306 responden menyatakan bahwa mereka lebih tertarik menyaksikan program Mata Najwa saat adanya episode menarik. Sedangkan 75 responden lainnya atau $20 \%$ menjawab bahwa mereka selama ini setiap minggunya "SERING MENYAKSIKAN PROGRAM MATA NAJWA" dan selalu mengikuti program tayangan Mata Najwa yang ditayangkan di Trans 7. Artinya, program Mata Najwa ini dipercaya responden Instagram polling sebagai program yang mengedukasi dan sebagai sumber informasi yang valid dan teraktual baik untuk semua tayangan dengan tema episode yang beragam dan pada saat episode yang hangat diperbincangkan.

Pada pertanyaan ketiga, sebanyak 368 responden atau 96\% berpendapat bahwa program Mata Najwa "MENDIDIK". Dan sebanyak 15 responden atau 4\% memilih program Mata Najwa "TIDAK MENDIDIK" Artinya responden pengguna Instagram memiliki tingkat kepercayaan yang tinggi kepada program televisi Mata Najwa. Program ini dirasa oleh pengguna Instagram sangat mendidik, menarik, berkualitas dan membentuk persepsi dan stigma yang positif terhadap tayangan ini.

Pertanyaan keempat dari total 377 responden sebanyak 3\% atau 13 responden menyatakan bahwa "TIDAK MENGINGINKAN PROGRAM MATA NAJWA TERUS ADA". Sedangkan 364 responden dengan persenyase 97\% mengatakan bahwa "MENGINGINKAN PROGRAM MATA NAJWA TERUS ADA". Artinya responden memiliki kepercayaan dan keyakinan yang sangat besar mengenai informasi yang disajikan dan diperbincangkan melalui tayangan program Mata Najwa. 
Dari pertanyaan kelima dengan total 380 responden, sebanyak 112 responden pengguna Instagram lebih memilih "MENYAKSIKAN PROGRAM BERITA UNTUK MENCARI INFORMASI PERISTIWA DAN BERITA TERHANGAT" dengan persentase sebesar 29\%. Sedangkan 268 dari 380 responden memilih untuk "MENYAKSIKAN PROGRAM MATA NAJWA UNTUK MENCARI INFORMASI PERISTIWA DAN BERITA TERHANGAT". Artinya masyarakat terutama para pengguna Instagram lebih memiliki ketertarikan tinggi terhadap tayangan program Mata Najwasebesar $71 \%$ dari $100 \%$. Artinya program Mata Najwa lebih memberikan informasi yang akurat dan intensif selain itu Najwa Shihab juga memiliki kemampuan persuasif yang baik.

Pertanyaan terakhir atau keenam memaparkan dari total 184 responden, sebanyak $73 \%$ atau 135 responden memilih "PROGRAM MATA NAJWA MEMPUNYAI DURASI YANG KURANG LAMA”. Dan selebihnya sebanyak 49 responden atau 27\% menyatakan, "PROGRAM MATA NAJWA MEMPUNYAI DURASI YANG TERLALU LAMA".

Selain itu, khusus pada pertanyaan keenam ini, penulis pun memberikan tambahan fitur Instagram Questions. Dimana responden dapat memberikan ide atau paparannya terhadap program Mata Najwa dalam bentuk tulisan. Total 27 responden yang mengisi dan mengutarakan paparannya pada fitur Instagram Question ini. Sebanyak 15 responden mengutarakan program Mata Najwa mempunyai durasi jam tayang yang “CUKUP”. Adapun kutipan pengguna Instagram Question berupa:

- @qorinayuniarti berpendapat, "Cukup, karena bahasannya padat, tidak berteletele, dan terbahas semuanya."

- @tiara.ro berpendapat, "Cukup, karena jika dipersingkat kurang meluas pembahasannya, jika diperlama jadi membosankan."

- @ledooo_berpendapat, "sangat mengedukatif"

Adapun yang memaparkan "PROGRAM MATA NAJWA MEMPUNYAI DURASI YANG KURANG LAMA" dengan respon berupa:

- @isnantororafly berpendapat, "kurang lama (durasi). Soalnya kalau dibahas banyak cut entah karena durasi segmen entah karena hal lainnya."

- @yogasedaw berpendapat, "kurang lama karena terkadang masih belom ada penyelesaian kongkrit dari perkaranya."

Adapun respon pengguna instagram terkait program Mata Najwa berupa:

- @ledooo_berpendapat, "sangat mengedukatif"

- @alifmirru berpendapat, "bahasa yang digunakan diplomatis banget dan membuat masyarakat lebih luas pandangannya, best lah."

Artinya respon dari responden pengguna Instagram memiliki opini dan pandangan tersendiri terhadap program Mata Najwa. Ini menunjukan bahwa pengguna Instagram yang menjadi responden memiliki ketertarikan terhadap program ini. 
Saifuddin Zuhri, Irvia Amananda dan Nanda Alya Karlina Amini dan Tiara Febri Angellia

\section{Kesimpulan}

Dari metode penelitian diatas menunjukkan bahwa program tayangan Mata Najwa Teori Uses and Gratifications yang menyatakan bahwa bagaimana media mengubah sikap dan perilaku khalayak. Teori Uses and Gratifications adalah khalayak pada dasarnya menggunakan media massa berdasarkan pada motif-motif tertentu.

Media dianggap memenuhi motif khalayak. Jika motif ini terpenuhi maka kebutuhan khalayak akan terpenuhi. Pada akhirnya, media yang mampu memenuhi kebutuhan khalayak disebut media efektif. Berdasarkan hasil penelitian dan pembahasan yang telah diulas diatas, menunjukan bahwa Mata Najwa telah menjadi media yang efektif bagi pengguna instagram. Dapat dilihat dari sebanyak 368 responden atau $96 \%$ berpendapat bahwa program Mata Najwa adalah program televisi yang mendidik. Mata Najwa mempunyai citra yang positif dan nilai edukasi dimata pengguna instagram. 
Menakar Respon Pengguna Instagram terhadap Program “Mata Najwa” Melalui Sisi dan Pandangan Politik

\section{BIBLIOGRAFI}

Effendy, Isaak, Löffler, Harald, \& Maibach, Howard I. (2000). Epidermal cytokines in murine cutaneous irritant responses. Journal of Applied Toxicology: An International Journal, 20(4), 335-341.

Fitria, Herlinda. (2013), Hiperrealitas Dalam Social Media (Studi Kasus: Makan Cantik di Senopati pada Masyarakaat Perkotaan).

Kennedy, H., Elgesem, D., \& Miguel, C. (2017). On Fairness: User Perspectives on Social Media Data Mining. From the International Journal of Research into New Media Technologies, Volume: 23 issue: 3 page(s): 270-288.

Kriyantono, Rachmat. 2009. Teknis Praktis Riset Komunikasi. Jakarta: Kencana Prenada Media Group.

Morissan. (2013). Teori komunikasi individu hingga massa. Jakarta: Prenada Media Group.

Meriyawati, M. (2015). Penggunaan diksi dan gaya bahasa najwa shihab pada acara mata najwa di metro tv. (skripsi). Jurusan Sastra Indonesia, Universitas Jember. Jember.

Nasrullah, R. (2017). Media sosial: Perspektif Komunikasi, budaya, dan sosioteknologi. Bandung: Simbiosa Rekatama Media.

Ngalimun. (2016). Ilmu Komunikasi sebuah pengantar praktis. Yogyakarta: PT Pustaka Baru Pressz.

Nuruddin, Molla Md, Madramootoo, Chandra A., \& Dodds, Georges T. (2003). Effects of water stress at different growth stages on greenhouse tomato yield and quality. HortScience, 38(7), 1389-1393.

Rahmah Alfafa I, Siti. (2017). e-skripsi: Motif Pengguna New Media (Studi Deskriptif Kuantitatif Pengguna Instagram di Kalangan Mahasiswa Fakultas Dakwah dan Komunikasi).

Rayanki, B. (2015). Rahasia dibalik program Mata Najwa on Stage. Yogyakarta: Institut Seni Indoensia Yogyakarta.

Romli, K. 2016. Komunikasi Massa. Jakarta: PT Grasindo.

Santosa, Hedi Pudjo. (2011). Isu-Isu Teoritis Media Sosial. Dalam Komunikasi 2.0 Teoritisasi dan Implikasi, Ed. Fajar Junaedi, 31-62. Yogyakarta: ASPIKOM.

Sugiyanto, D. R. (2015). Komodifikasi Berita Dibalik Ideologi Eknomi Politik Media (Studi Pada Program 'Polemik' di Radio Sindo Trijaya 104.6 Fm Jakarta). Jurnal Komunikasi, Vol. 7 , No, 57-69. 
Saifuddin Zuhri, Irvia Amananda dan Nanda Alya Karlina Amini dan Tiara Febri Angellia

Syahreza, Muhammad Fachri, \& Tanjung, Irwan Syari. (2018). Motif dan Pola Penggunaan Media Sosial Instagram di Kalangan Mahasiswa Program Studi Pendidikan Ekonomi Unimed. Jurnal Interaksi: Jurnal Ilmu Komunikasi, 2 (1), 61-84.

Tekkay, Alfrini, Himpong, Meity, \& Paputungan, Ridwan. (2017). Persepsi Masyarakat Tentang Talkshow "Mata Nadjwa" Di Metro Tv (Studi Pada Masyarakat Bahu Kecamatan Malalayang). Acta Diurna Komunikasi, 6 (2).

Wardani Anindia Pramura. (2015). Konstruksi Diri Dalam Sosial Media. Skripsi Universitas Sebelah Maret Surakarta.

Wahid, A. (2014). Menakar Kualitas Public Sphere di Tengah Benang Kusut Sistem Media Indonesia. Jurnal Literasi Ilmukomunikasi Dan Multimedia Universitas Mercu Buana Yogyakarta, Voulme 1 N.

Wenerda, I. (2015). Ekonomi Politik Vincent Moscow oleh Media Online Entertainment kapanlagi.com ${ }^{\mathrm{TM}}$. Channel diterbitkan oleh Fakultas Sastra dan Budaya Universitas Ahmad Dahlan Yogyakarta, Vol. 3 No1, 1-14. 